\title{
Psychometric Characteristics of the Physical Activity Enjoyment Scale in the context of Outdoor Activity
}

\author{
Julio Fuentesal-García ${ }^{1}$, Antonio Baena-Extremera ${ }^{2}$ and Jesús Sáez-Padilla ${ }^{3, *}$ \\ 1. Affiliation 1; jfuentesal@cesdonbosco.com \\ Correspondence: jfuentesal@cesdonbosco.com; Tlf: +34-654832302 \\ 2. Affiliation 2; abaenaextrem@ugr.com \\ Correspondence: abaenaextrem@ugr.com; Tlf: 34+619342694 \\ 3 Affiliation 3; jesus.saez@dempc.uhu.es \\ Correspondence: jesus.saez@dempc.uhu.es; Tel: +34-679096680
}

\begin{abstract}
The aim of this study was to assess the psychometric properties of the Physical Activity Enjoyment Scale in the context of outdoor physical activities. In order to do this, we carried out a research in some Primary and Secondary school 1 located in western Andalucía (Spain), with kids aged 9-12 years old [M=11.22; $\mathrm{SD}=1.07)$, therefore a sample of 455 students $(228$ boys= 50.1\% 227 girls $=49.9 \%=50.1$ ) was used]. Descriptive, exploratory and confirmatory analyses were conducted. We also analyzed several factors such as internal consistency, composite reliability, average variance extracted and convergent validity. Afterwards, differences by gender and school year were also studied. Data showed the need to eliminate many of the items from the original scale, giving as a result a model of 5 items with satisfactory fit in the confirmatory analysis. The ANOVA statistical test carried out in terms of sex and school year didn't show any tangible difference between the target groups.
\end{abstract}

Keywords: enjoyment; outdoor activities: education; physical activity

\section{Introduction}

We have in recent years witnessed an important increase in physical activity levels in the general population [1]. The rise in the number of hours devoted to physical activity plus the variety of spaces and places where it can be carried out have transformed the outdoors into one of the main scenarios for this type of activity [2]. Enjoyment and pleasure are some the reasons behind the increase in the practice of physical activity. Enjoyment in the context of physical activity is specifically defined as a positive cognitive or physiologic state which involves feelings of pleasure and fun related to the practice of physical activity [3]. The outdoors have become an ideal place to escape from society, routine, and life stress, and basically an ideal place to go back to the essence of being oneself. Being in contact with nature also brings with it multiple personal benefits [4]. 21 ${ }^{\text {st }}$ century sports practice is also particularly focused on enhancing the experience of strong emotions and exciting sensations, and on an idea of intense enjoyment that drives athletes to test their personal limits (challenges) by exploring strange and unusual spaces, in short, on searching for adventure and risk [5]. This implies spending more leisure time and doing physical activity in outdoor spaces in order to counter city life as $75 \%$ of the European population live in urban environments [6].

Outdoor physical activity entails sports-physical activities embodied in educational legislation. That start to be practiced at school with the aim of instilling future habits in the population [4]. One of the main characteristics of these outdoor sport disciplines is enjoyment, which is in turn one of the central motivations for people to practice sports [7]. Following Scanlan and Symons [8] enjoyment involves feeling pleasure, joy and fun. In this regard, Granero-Gallegos et al. [9] have shown the 
relationship existing, for instance, between students "enjoying sports practice and subjects" intrinsic motivation (according to Self-Determination Theory [10]) the importance that students attribute to the Physical Education subject, and more importantly, the intention of doing physical activity in the future.

Enjoyment has been studied from different theoretical perspectives in the search of an explanation of the relationship it has with physical and sports practice as it is seen as a key factor in this regard [11].Thus, it has been associated with perceived athletic competence and with the factors mentioned in the previous paragraph [12].

A series of instruments have been used to assess enjoyment in physical activity e.g. the Subjective Exercise Experiences Scale (SEES) [13] and the Enjoyment Scale as a dimension of achievement motivation [14]. In this study we used the instrument proposed by Molt et al. [15] given that it is one of the most relevant in terms of psychometric results. This instrument includes 16 items and it has been adapted for adolescents; a series of studies reveal an interesting relationship between enjoyment and the different versions of intrinsic motivation [16].

Bearing in mind the increase in number of people doing physical activity and sports and the importance that the outdoors are gaining for this practice, we propose the hypothesis that the PACES will be well adapted to the student population in the context of outdoor physical activity. Thus, the object of this study is to analyze the psychometric characteristics of the PACES in a sample of 9-13 years old students in a context of outdoor physical activity practice using confirmatory procedures, and finally a gender and school year analysis. It is worth noting that these practices have certain educational connotations $[5,17]$ and also that there is a serious lack of research in the field of physical activity and the outdoors.

\section{Materials and Methods}

\subsection{STUDY 1}

\subsubsection{Design}

In terms of the sample, a non-probabilistic convenience design was applied, based on the subjects that could be accessed. The design used was non-experimental, sectional, descriptive and exploratory.

\subsubsection{Participants and procedure}

A total of 205 students ( 98 boys and 107 girls) participated in this study, the age range being $12-13$ years old $(\mathrm{M}$ age $=12.22, \mathrm{SD}=0.57)$, all being $1^{\text {st }}$ and $2^{\text {nd }}$ year high school students in different educational centers in western Andalusia, Spain. Students, parents and schools' management were briefed on data collection. Once authorizations were obtained instructions were given and doubts were cleared up prior to filling in the questionnaires. The questionnaires were answered voluntarily anonymously way upon arrival at the camp site (Albergue Campamento de Andévalo Aventura SLL) in approximately 20 minutes.

\subsubsection{Instrument and adaptation to the Outdoor Physical Activity context}

We used the Physical Activity Enjoyment Scale (PACES) [15] adapted to the Spanish context by Moreno et al. [16]. This scale measures enjoyment during physical activity through 16 items, which are preceded by the phrase "When I am active...". This instrument measures enjoyment, bipolar enjoyment, through statements such as "I enjoy it", "I'm bored", "It's very exciting", "I don't like it", etc. The answers were collected on a polytomic scale from 1 (totally disagree) to 5 (totally agree).

The final version obtained was analyzed by a group of four experts (Lynn, 1986) in education and outdoor physical activity in order to ensure the appropriate design of the items in terms of what the 
construct was intended to measure; the original meaning was maintained [18]. These experts were given a table with the items specifications [19] which collected the semantic definition of the construct to be assessed and that of its component. Next, they were shown the list of items after they were adapted so that they could give their opinion on their suitability and understandability on a scale from 1 (totally disagree) to 4 (totally agree). Furthermore, there was a section where they could write general notes and observations on each of the items, and write an alternative version for each item if they saw fit. The items with $<2.5$ mean scores, both in terms of suitability and understandability, were revised. If an item was not classified by at least three of the four experts as within the theoretical dimensions of the scale it was revised again to analyze potential problems before proposing an alternative wording which would cover the theoretical dimension in a more clear and accurate way. The overall agreement of the four experts on the suitability and understandability of the items was measured using the Intraclass Correlation Coefficient (ICC) based on a mixed effects model and assuming an absolute agreement definition; the values obtained were $\mathrm{CCI}=0.77$ in suitability and $\mathrm{CCI}=0.80$ in understandability.

Furthermore, the interquartile range was the standard used in order to measure dispersion in the four experts' agreement. If the difference between percentile 3 and percentile 1 equaled 0 or 1 , the item was accepted and/or slightly modified; if this difference was between 1 and 2, the item was revised and reformulated, and if it was higher than 2 it meant the dispersion between experts was too high and the item was rejected. Finally, the experts' comments regarding the instructions and their wording resulted in minor changes. The new version was administered to sixty five 12 - 13 year old high school students. They confirmed their full understanding of the items and after a final revision by the research team we obtained the final version of the PACES adapted to Outdoor Physical Activity.

\subsubsection{Data Analysis}

The psychometric properties of the Physical Activity Enjoyment Scale adapted to outdoor activities for school students were analyzed through the statistical analysis of the items; an exploratory factor analysis. SPSS Statistics 21 was used for data analysis.

\subsection{STUDY 2}

\subsubsection{Design}

In terms of the sample, a non-probabilistic convenience design was used, based on the subjects that could be accessed. The design used was non-experimental, sectional, descriptive and exploratory.

\subsubsection{Participants and procedure}

A total of 455 students (228 boys and 227 girls) participated in this study, the age range being -13 years old $(\mathrm{M}$ age $=11.22, \mathrm{SD}=1.07)$, all being primary school $5^{\text {th }}$ and $6^{\text {th }}$ years and $1^{\text {st }}$ and $2^{\text {nd }}$ high school students in different educational centers in western Andalusia, Spain. Students, parents and schools' managements were briefed on data collection. Once authorizations were obtained instructions were given and doubts were cleared up prior to filling in the questionnaires. The questionnaires were answered voluntarily and anonymously upon arrival to the camp site (Albergue Campamento de Andévalo Aventura SLL) in approximately 20 minutes.

\subsubsection{Instrument}

We used the Physical Activity Enjoyment Scale (PACES) adapted to outdoor physical activity described in Study 1.

\subsubsection{Data analysis}

We carried out a CFA and reliability was measured through Cronbach's alpha. Average variance extracted, composite reliability and McDonald's $\omega$ were also estimated. Convergence validity and 
gender invariance as well as gender and school year differences were measured with Student's $t$ and ANOVA. Data analysis was carried out with SPSS Statistics 21.0 and LISREL 8.80 [19].

\section{Results}

\subsection{STUDY 1}

\subsubsection{Descriptive Analysis}

First, we carried out the analysis of each of the items in the scale following the suggestions in Carretero-Dios et al. [21]. In line with the contributions in Nunnally et al. [22], we analyzed whether the internal consistency of the scale increased with the elimination of any of the items and the particularities necessary to keep an item inside a factor were studied: corrected item-total correlation (C-ITC), coefficient, standard deviation (SD), and all the answer options used at some point. Moreover, skewness and kurtosis indices had to be close to 0 and $<2$ for these items to be accepted. Initially, we tried using only one factor, as done in the original versions, but data was not satisfactory and even less so was the Cronbach's alpha value. In view of this, we opted for distinguishing two factors, a negative valency and a positive valency of enjoyment.

Table 1. Descriptive, internal consistency and homogeneity statistics $(\mathrm{N}=205)$

\begin{tabular}{lllllll}
\hline Scale: & $M$ & $S D$ & CCIT- $c$ & $\alpha$ sin & Asimetría & Curtosis \\
\hline \multicolumn{1}{c}{ Positive Enjoyment $(\alpha=.786)$} & & & & & & \\
\hline 1. I enjoy it & 4.67 & .770 & .51 & .76 & -2.92 & 9.39 \\
4. I find it pleasant & 4.39 & .948 & .50 & .76 & -1.75 & 2.87 \\
6. It gives me energy & 4.12 & 1.13 & .53 & .76 & -1.31 & .983 \\
8. It's very exciting & 4.46 & .916 & .57 & .75 & -1.86 & 3.24 \\
9. My body feels good & 4.31 & .957 & .54 & .76 & -1.50 & 1.85 \\
10. I get something extra form & 3.87 & 1.19 & .45 & .77 & -.880 & -.030 \\
11. It's very exciting & 3.97 & 1.23 & .45 & .77 & -1.05 & .150 \\
14. It produces strong feelings in me & 3.23 & 1.35 & .32 & .80 & -.319 & -.960 \\
15. I feel good & 4.60 & .792 & .55 & .76 & -2.38 & 5.97 \\
\hline Negative Enjoyment $(\alpha=.700)$ & & & & & & \\
\hline 2. I'm bored & 1.46 & .906 & .42 & .66 & 2.23 & 4.94 \\
3. I don't like & 1.35 & .857 & .39 & .67 & 2.75 & 7.36 \\
5. It's no fun at all & 1.41 & 1.04 & .39 & .67 & 2.59 & 5.77 \\
7. It depresses me & 1.32 & .885 & .47 & .65 & 2.96 & 8.11 \\
\hline 12. It frustrates me & 1.35 & .881 & .46 & .65 & 2.76 & 7.22 \\
13. It's not at all interesting & 1.31 & .839 & .35 & .68 & 2.91 & 7.98 \\
16. I think I should be doing something else & 1.00 & .39 & .67 & 2.21 & 4.11 \\
\hline
\end{tabular}

An analysis of the items and factors revealed that the alpha values can be deemed acceptable. In spite of this, the SD results obtained in many of the items have problems (Items 1, 2, 3, 4, 7, 8, 9, 12, 13, and 15 ) as their values range between .770 and .957 . Furthermore, the skewness values of the negative enjoyment items are above 2.21, and kurtosis values are above 4.11. In the case of positive enjoyment, many of the items $(1,4,8,15)$ show skewness ( -2.38 to -2.92$)$ and kurtosis values (3.24 a 9.39) which 
suggest they should be eliminated. However, it is worth noting that the alpha value of each factor did not increase if the problematic items were deleted. Furthermore, the C-ITC of all the items showed values $\geq .32$, so we assumed the possibility of using these items in the scale.

\subsubsection{Exploratory factor analysis (EFA)}

An EFA for one factor was carried out and the data ruled out this structure. Therefore, a two-factor EFA solution was carried out using principal component analysis (PCA) requiring a .40 minimum correlation for each item to be important within a factor [23]. The Kaiser-Meyer-Olkin measure was adequate (.89), and Bartlett's test was statistically significant $\left(\chi^{2}=1658.55, \mathrm{p}<.000\right)$, all of which verified the suitability of the EFA. The results confirm the two-factor extraction (Table 2). However, the explained variance was low, with a $39.2 \%$ value for the total scale.

Table 2. Rotated component matrix ( $\mathrm{N}=205)$.

\begin{tabular}{|c|c|c|}
\hline Scale: & $F 1$ & $F 2$ \\
\hline \multicolumn{3}{|l|}{ Positive Enjoyment ( $\alpha=.786$ ) } \\
\hline 1. I enjoy it & & .411 \\
\hline 4. I find it pleasant & & .518 \\
\hline 6. It gives me energv & & .585 \\
\hline 8. It's verv exciting & & .537 \\
\hline 9. My body feels good & & .581 \\
\hline 10. I get something extra form & & .715 \\
\hline 11. It's verv exciting & & .597 \\
\hline 14. It produces strong feelings in me & & .554 \\
\hline 15. I feel good & & .440 \\
\hline \multicolumn{3}{|l|}{ Negative Enjoyment $(\alpha=.700)$} \\
\hline 2. I'm bored & .549 & \\
\hline 3. I don't like & .531 & \\
\hline 5. It's no fun at all & .505 & \\
\hline 7. It depresses me & .685 & \\
\hline 12. It frustrates me & .625 & \\
\hline 13. It's not at all interesting & .479 & \\
\hline 16. I think I should be doing something else & .560 & \\
\hline
\end{tabular}

\subsection{STUDY 2}

\subsubsection{Confimatory Factor Analysis}

Structural equation modeling was applied in order to study the psychometric properties of the PACES adapted to its outdoor physical activity original dimension. A series of absolute and relative fit indices were estimated to assess the models [24,25]. In terms of absolute fit indices, we used $p$ value associated with the Chi-square statistic $\left(\chi^{2}\right)$; the ratio between $\chi^{2}$ and degrees of freedom (d.f.) ( $\chi^{2} /$ d.f.), and GFI (Goodness of Fit Index). As to relative indices, we analyzed NNFI (Non-Normed Fit Index) and CFI (Comparative Fit Index). The RMSEA (Root Mean Square Error of Approximation) was also estimated as the incremental index. The parameters are considered significant when the $t$ value associated is above $1.96(\mathrm{p}<.05)$. 
First, a multivariate normal distribution analysis was carried out for this scale using the normality test based on the relative multivariate kurtosis (RMK) of PRELIS, LISREL 8.80. The PACES normalized multivariate kurtosis was 32.4 (Mardia-Based-Kappa = .726). The critical test value was $1.96(5 \%)$. The test results rejected multivariate normality, which implies the use of robust estimators. In view of this, we used the weighted least squares (WLS) method in LISREL 8.80 [20]. The polychoric correlation matrix and the asymptotic covariance matrix were used as input for data analysis. A two-factor measurement model was hypothesized. The calculations revealed that the RMSEA values as well as some of the factor loads (item $14=.37$ ) and individual reliability $\left(R^{2}\right)>.50$ ) of many of the items were not suitable (Table 3). Following Byrne [26], the items with high values in standardized residuals (> \pm 2.58 ) were considered for potential elimination.

Table 3. Items individual reliability $(\mathrm{N}=455)$

\begin{tabular}{|c|c|c|}
\hline Scale: & Load & $R^{2}$ \\
\hline \multicolumn{3}{|l|}{ Positive Enjoyment $(\alpha=.786)$} \\
\hline 1. I enjoy it & .79 & .624 \\
\hline 4. I find it pleasant & .67 & .455 \\
\hline 6. It gives me energy & .65 & .423 \\
\hline 8. It's very exciting & .77 & .600 \\
\hline 9. My body feels good & .66 & .429 \\
\hline 10. I get something extra form & .49 & .238 \\
\hline 11. It's very exciting & .55 & .307 \\
\hline 14. It produces strong feelings in me & .37 & .140 \\
\hline 15. I feel good & .80 & .632 \\
\hline \multicolumn{3}{|l|}{ Negative Enjoyment $(\alpha=.700)$} \\
\hline 2. I'm bored & .66 & .435 \\
\hline 3. I don't like & .71 & .500 \\
\hline 5. It's no fun at all & .67 & .455 \\
\hline 7. It depresses me & .76 & .580 \\
\hline 12. It frustrates me & .70 & .486 \\
\hline 13. It's not at all interesting & .65 & .423 \\
\hline 16. I think I should be doing something else & .62 & .386 \\
\hline
\end{tabular}

This data plus that in Table 1 suggests eliminating items with low values. The CFA values were $\chi^{2} /$ d.f. $=4.75 ; \mathrm{p}<.000 ; \mathrm{RMSEA}=.09 ; \mathrm{ECVI}=1.223 ; \mathrm{NNFI}=.950 ; \mathrm{CFI}=954 ; \mathrm{IFI}$. 954; GFI= .881. Thus, following Markland [25] and Levy and Hancock [27], we carried out a series of analyses of different models as suggested by the data, and those items with low factor load and low $R^{2}$ were eliminated. The final result was a PACES-OPACT with a two-factor model with six items whose EFA values were: $\chi^{2} /$ d.f. $=.65 ; \mathrm{p}<.000 ; \mathrm{RMSEA}=.005(\mathrm{IC} 90 \%=.004, .006) ; \mathrm{ECVI}=.057 ; \mathrm{NNFI}=1.002 ; \mathrm{CFI}=1.00$; $\mathrm{IFI}=1.001$ and $\mathrm{GFI}=.998$ (Table 4$)$. 
Table 4. Items individual reliability $(\mathrm{N}=455)$

\begin{tabular}{lcc}
\hline Scale & Load & $R^{2}$ \\
\hline Positive enjoyment $(\alpha=.712)$ & & \\
1. I enjoy it & .74 & .552 \\
8. It's very pleasant & .75 & .560 \\
15. I feel fine & .84 & .702 \\
\hline Negative enjoyment $(\alpha=.716)$ & & \\
3. I don't like me & .73 & .560 \\
7. It depresses me & .80 & .640 \\
12. It frustrates me & .75 & .566 \\
\hline
\end{tabular}

The table 4 shows the fit indices of the two-factor six item model, which was the only one with the minimum requirements to guarantee convergent validity [28] high standardized factor loads (>.60) which are statistically significant (t-value $>1.96)$. Finally, in view of the low alpha values in the ordinal EFA of scales in the correlation matrix, it is also interesting to provide the EFA composite reliability and Average Variance Extracted (AVE) values for each dimension. The AVE reflects the total variance of the indicators collected by the latent construct; the higher the value, the more representative the indicators of the critical dimension to which they are loaded. In view of the limitations of the Cronbach's alpha [29], especially when the variables include a low number of items [30] as is the case of the instrument analyzed in this study. McDonald's $\omega$ was calculated to measure reliability given that, unlike the alpha coefficient, it takes into account the factor loads. Thus, the calculations are more stable and reflect the actual reliability level regardless of the number of items in the variable [29]. Internal consistency values $(\omega)$ are considered suitable when they are in the .70 - .90 range [31].

Table 5. Scale reliability and validity

\begin{tabular}{lccc}
\hline PACE - Five item mo- & Convergent Validity & AVE & Cronbach's \\
\hline Positive Enjoyment & .82 & .60 & .85 \\
\hline Negative Enjoyment & .75 & .60 & .85 \\
\hline
\end{tabular}

In terms of convergent validity, that the validity of indicators can be assessed based on the size of factor loads [32]. Thus, the NFI was .943 for the 16 item scale, whereas for the six item instrument, this value was .998. As to the AGFI, it was .843 for the 16 item model, and .991 in the case of the five item model. Further to this, as mentioned above, saturation was in all cases statistically significant ( $\mathrm{t}$-value $>1.96$ ), which means that al indicators are assessing the same theoretical construct [33]. Finally, it is worth noting that all the items have high factor loads $\left(\mathrm{R}^{2}>.50\right)$. 


\subsubsection{Gender and school year differences}

Next, in order to analyze gendered differences, we carried out a Student's $t$ for independent samples and an ANOVA to study school year differences. As seen in Table 6, no gendered differences were found in terms of positive and negative enjoyment of OPACT in any of the independent variables.

Table 6. Variance analysis according to gender and school year

\begin{tabular}{|c|c|c|c|c|c|c|c|c|c|c|c|c|c|c|c|c|}
\hline & \multicolumn{2}{|c|}{$\begin{array}{l}\text { Male } \\
(\mathrm{n}=228)\end{array}$} & \multicolumn{2}{|c|}{$\begin{array}{l}\text { Female } \\
(n=227)\end{array}$} & \multirow[b]{2}{*}{$F$} & \multirow[b]{2}{*}{$n$} & \multicolumn{2}{|c|}{$\begin{array}{l}5^{\text {th }} \text { Pri- } \\
\text { mary }\end{array}$} & \multicolumn{2}{|c|}{$\begin{array}{l}6^{\text {th }} \text { Pri- } \\
\text { mary }\end{array}$} & \multicolumn{2}{|c|}{$\begin{array}{l}1^{\text {st }} \text { ESO } \\
(\mathrm{n}=17)\end{array}$} & \multicolumn{2}{|c|}{$\begin{array}{l}2^{\text {nd }} \text { ESO } \\
(n=29)\end{array}$} & \multirow[b]{2}{*}{$F$} & \multirow[b]{2}{*}{$n$} \\
\hline & $M$ & $s D$ & $M$ & $S D$ & & & $M$ & sח & $M$ & $S D$ & $M$ & $s D$ & $M$ & $s D$ & & \\
\hline PEPS & & & & & & & & & & & & & & & & \\
\hline Positive Enjoy- & 4.61 & .62 & 4.53 & .68 & 1.81 & .18 & 4.62 & .55 & 4.58 & .65 & 4.15 & .86 & 4.66 & .52 & 2.59 & .052 \\
\hline Negative Enjo- & 1.28 & .73 & 1.39 & .80 & 2.25 & .13 & 1.25 & .66 & 1.33 & .74 & 1.47 & .72 & 1.37 & .67 & .317 & .813 \\
\hline
\end{tabular}

\subsubsection{Invariance analysis}

A gendered invariance analysis was carried out (Table 7) in order to simultaneously test the equivalence of the factor structure of both sub-groups. No significant differences were found between Model 1 (model with no restrictions) and Model 2 (invariance in measurement loadings) ( $p$ $=.536$ ), or between Model 1 and Model 3 (invariant structural variances and covariances) ( $p$ $=.378)$. However, statistically significant differences were observed between Model 1 and Model 4 (invariant measurement residuals) $(p=.037)$. According to Byrne (2013), the absence of statistically significant differences between Model 1 and Model 2 constitutes a minimum standard to accept the existence of invariance in the model, in this case in terms of gender. Moreover, the decrease in the CFI values was also taken into account; they were $<0.1$ ( $\triangle$ CFI contrast test) across the different models, so following Cheung and Rensvold [34] the model was proved to be gender invariant.

Table 7. Multigroup invariance analysis in relation to the gender variable

\begin{tabular}{lccccccc}
\hline Models & $\chi^{2} / \mathrm{df}$ & $\Delta \chi^{2}$ & $\Delta \mathrm{gl}$ & CFI & TLI & GFI & RMSEA (IC 90\%) \\
\hline Model 1 & .65 & - & - & 1.00 & 1.00 & .99 & $.005(.004-.006)$ \\
Model 2 & .96 & 12.05 & 12 & 1.00 & .98 & .98 & $.006(.005-.007)$ \\
Model 3 & .90 & 23 & 21 & 1.00 & .97 & .98 & $.006(.005-.007)$ \\
Model 4 & .98 & 77.37 & 18 & .99 & .97 & .98 & $.007(.006-.008)$ \\
\hline
\end{tabular}

Note. $\chi^{2}=$ chi-squared; $\mathrm{df}=$ degrees of freedom; $\mathrm{CFI}=$ comparative fit index; TLI = Tucker-Lewis index; SRMR = standardized root-mean-square residual ; RMSEA = root-mean-square error of approximation.

\section{Discussion}

The main objective of this work was to analyze the psychometric characteristics of the PACES scale in a context of outdoor physical activity for a group of primary and secondary Physical Education students. We have followed the lines set out in Crocker et al. [35] relation to the usefulness of this scale to measure enjoyment in different physical education areas; that is, we have used a bi-dimensional fit model of the construct. 
Outdoor physical activity is included in the Physical Education classes that the students in this study take during school hours [5]. They work on contents such as orientation, hiking, outdoor games, gymkhanas, knotting, climbing, mountain biking, etc. [36]. Furthermore, other studies have proved the beneficial effects of this type of activities for students when physical activity is carried out outdoors as it improves aspects such as satisfaction and fun in class, self-perception and even social goals $[37,38,39,40]$. In view of all this, it is essential to present the new instrument in this study given that it will help promote the advancement of knowledge in the field outdoor physical activity, Physical Education and Sports-Physical Activity.

The analyses carried out have shown that the original 16 item scale would not be valid to meet the objective of analyzing students in this context and thus it would be necessary to reduce the scale. First, the descriptive, internal consistency and homogeneity values clearly revealed the need to modify the scale by eliminating some of the items as they showed problems. This was then confirmed by the CFA, which clearly showed that the scale had to be reduced in order to fall within the fit indices' acceptable values, and many of the items had factor loading and individual reliability problems. This reduction in the scale is also interesting for primary school students given that for them it would be more suitable to assess variables through 5 rather than 16 questions if the results allow for this and their answers are likely to be more reliable in relation to longer questionnaires.

Another relevant aspect is that the scale did not show good fit for one factor taking into account the original Molt et al. [15] version adapted to Spanish by Moreno et al. [16]. It should be noted that in other studies [41] factorial structure of the scale was not analyzed, suggesting its future analysis in later works and with other broader samples. However, other [42] did perform this analysis with adolescent population, also finding problems in their one-dimensional adjustment. Their part [36] confirmed this one factor structure with an inactive adult population and obtained good values. In this present case, both the exploratory and especially the case of the confirmatory analysis only allowed the two-factor version of enjoyment by distinguishing between positive and negative enjoyment.

As to the ANOVA and invariance analyses, no gendered or school year differences were found. In terms of gender, enjoyment constitutes, particularly relevant factor in the study of behavior in physical activity as it has been consistently shown to be related to female participation [43, 28]. Moreover, others authors $[45,46]$ that in teenage girls enjoyment is a consistent predictor of physical activity. The lack of significant differences might be related to various factors. One is that a large part of the sample analyzed was made up of primary school students, and it is worth noting here that in this education stage outdoor physical activity is less frequent than in secondary school. This means that students have covered fewer contents (outdoor physical activity does not exist as such in primary school and it is included through games and sports) and therefore there is a very low level of gendered differences. Likewise, primary school teacher training courses are different from secondary education teacher training. Sports Science degrees include an outdoor activity compulsory subject [47], opposed to primary school teacher degrees, where in most cases this subject is not taught. This means that outdoor physical activity contents are virtually absent through primary school, except when teachers are particularly interested in this field; hence the difficulty in finding significant differences.

\section{Conclusions}

To conclude, it is worth noting that the PACES-OPACT has partially verified the hypothesis given that it has not fully adapted and it has been necessary to create a six item model. This model shows a very good fit as shown by the CFA, and has high reliability and validity (see Table 5). The convergent validity values also provide this data with robustness. 
However, and in terms of potential future perspectives, it would be good to contrast these results differentiating a primary school sample and a secondary school sample, and with outdoor physical activity contents taught exclusively at schools or exclusively outside schools. It is important to note that the location of schools and the extra-mural outdoor activities that students may carry out, such as scouting groups, as well as closeness to natural environments, etc., change the vision and knowledge on these contents [48] view of all this, we believe that although the data provided fully support its application, it would be interesting to contrast these results with future studies.

Author Contributions: Conceptualization, J.F.-G., J.S.-P. and A.B.-E.; Methodology, J.F.-G., J.S.-P. and A.B.-E.; Formal Analysis, J.F.-G., J.S.-P. and A.B.-E.; Resources, J.F.-G., J.S.-P. and A.B.-E.; Writing-Review and Editing, J.F.-G., J.S.-P. and A.B.-E..

Funding: This research received no external funding.

Conflicts of Interest: The authors declare no conflict of interest.

\section{References}

1. Baggish, A. L.; Battle, R. W.; Beckerman, J. G.; Bove, A. A.; Lampert, R. J.; Levine, B. D.; et al. Sports Cardiology: Core Curriculum for Providing Cardiovascular Care to Competitive Athletes and Highly Active People. Journal of the American College of Cardiology, 2017, 70(15), 1902-1918.

2. Tarun, S.; Arora, M.; Rawal, T.; Benjamin, S. E. An evaluation of outdoor school environments to promote physical activity in Delhi, India. BMC Public Health, 2017, 17(1), 11.

3. Shaw, B.; Shaw, I. Determinants of physical activity in children and adolescents: implications for the increasing prevalence of childhood obesity. African Journal for Physical Health Education, Recreation and Dance. A multi-disciplinary approach to Heal. Well-being, 2014, 20, 91-101.

4. Sáez-Padilla, J.; Tornero, I.; Sierra, A. Ocho razones para fomentar el aula naturaleza desde la educación física. Cuadernos de Pedagogía, 2017, 479, 48-51.

5. Granero-Gallegos, A.; Baena-Extremera, A. (2014). Actividades en el medio natural, aula y formación del profesorado. Tándem, Didáctica de la Educación Física, 2014, 45.

6. Gascon, M.; Zijlema, W.; Vert, C.; White, M. P.; Nieuwenhuijsen, M. J. Outdoor blue spaces, human health and well-being: A systematic review of quantitative studies. International Journal of Hygiene and Environmental Health, 2017, 220(8), 1207-122.

7. Castillo, I.; Balaguer, I. Dimensiones de los motivos de práctica deportiva de los adolescentes valencianos escolarizados. Apunts: Educación Física y Deportes, 2001, 63, 22-29.

8. Scanlan, T. K.; Simons, J. P. The construct of sport enjoyment. En G. C. Roberts (Ed.), Motivation in sport and exercise. Champaign, IL: Human Kinetics, 1992, 199-215.

9. Granero-Gallegos, A.; Baena-Extremera, A.; Sánchez-Fuentes, J. A.; Martínez-Molina, M. Perfiles motivacionales de apoyo a la autonomía, autodeterminación, satisfacción, importancia de la educación física e intención de práctica física de tiempo libre. Cuadernos de Psicología del Deporte, 2014, 14(2), 59-70.

10. Ryan, R. M.; Deci, E. L. Self-determination theory and the facilitation of intrinsic motivation, social development and well-being. American Psychologist, 2000, 55, 68-78.

11. Scanlan, T. K.; Carpenter, P.; Schmidt, G.; Simons, J.; Keeler, B. (1993). An introduction to the Sport Commitment Model. Journal of Sport \& Exercise Psychology, 1993, 15, 1-15.

12. Davison, K. K.; Werder, J. L.; Trost, S. G.; Baker, B. L.; Birch, L. L. Why are early maturing girls less active? Links between pubertal development, psychological well-being and physical activity among girls at ages 11 and 13. Social Science \& Medicine, 2007, 64, 2391-2404.

13. McAuley, E.; Courneya, K. S. The Subjective Exercise Experiences Scale (SEES): Development and preliminary validation. Journal of Sport and Exercise Psychology, 1994, 16(2), 163-177.

14. Duda, J. L.; Nicholls, J. G. Dimensions of achievement motivation in schoolwork and sport. Jounal of Educational Psychology, 1992, 84(3), 290-299. 
15. Molt, R. W.; Dishman, R. K.; Saunders, R.; Dowda, M.; Felton, G.; Pate, R. R. Measuring enjoyment of physical activity in adolescent girls. American Journal of Preventive Medicine, 2001, 21, 110-117.

16. Moreno, J. A.; González-Cutre, D.; Martínez, C.; Alonso, N.; López, M. Propiedades psicométricas de la Physical Activity Enjoyment Scale (PACES) en el contexto español. Estudios de Psicología, 2008, 29(2), 173-180.

17. Granero-Gallegos, A.; Baena-Extremera, A. Importancia de los valores educativos de las actividades físicas en la naturaleza. Habilidad Motriz, 2007, 29, 5-14.

18. Muñiz, J.; Elosua, P.; Hambleton, R. K. Directrices para la traducción y adaptación de los tests: Segunda edición. Psicothema, 2013, 25(2), 151-157.

19. Spaan, M. Test and item specifications development. Language Assessment Quarterly, 2006, 3(1), 71-79.

20. Jöreskog, K.; Sörbom, D. LISREL 8.54. Structural equation modeling with the simplis command language. Chicago: Scientific Software International, 2003.

21. Carretero-Dios, H.; Pérez, C. (2007). Standards for the development and the review of instrumental studies: Considerations about test selection in psychological research. International Journal of Clinical and Health Psychology, 2007, 863-882.

22. Nunnally, J. C.; Bernstein, I. J. Teoría psicométrica. Madrid: Mcgraw-Hill, 1995.

23. Stevens, J. P. Applied multivariate statistics for the social sciences (2nd edition). Hillsdale: Erlbaum. 1992.

24. Bentler, P. M. On tests and indices for evaluating structural models. Personality and Individual Differences, 2007, 42(5), 825-829.

25. Markland, D. The golden rule is that there are no golden rules: A commentary on Paul Barrett's recommendations for reporting model fit in structural equation modelling. Personality and Individual Differences, 2007, 42(5), 851-85.

26. Byrne, B. M. Structural equation modeling with AMOS: Basic concepts, applications, and

programming. Londres: Routledge, 2013.

27. Levy, R.; Hancock, G. R. A. framework of statistical tests for comparing mean and covariance structure models. Multivariate Behavioral Research, 2007, 42, 33-66.

28. Raedeke, T. D. The relationship between enjoyment and affective responses to exercise. Journal of Applied Sport Psychology, 2007, 19, 105-115.

29. Hair, J. F.; Black, W. C.; Babin, B. J.; Anderson, R. E. Multivariate Data Analysis (7th ed.). New York: Pearson Prentice Hall, 2009.

30. Ventura-León, J. L.; Caycho-Rodríguez, T. El coeficiente Omega: un método alternativo para la estimación de la confiabilidad. Revista Latinoamericana de Ciencias Sociales, Niñez y Juventud, 2017, 15(1), 625-627.

31. Domínguez-Lara, S. A. D.; Merino-Soto, C. M. ¿Por qué es importante reportar los intervalos de confianza del coeficiente alfa de Cronbach? Revista Latinoamericana de Ciencias Sociales, Niñez y Juventud, 2015, 13(2), 1326-1328.

32. Campo-Arias, A.; Oviedo, H. C. (2008). Propiedades psicométricas de una escala: la consistencia interna. Revista de Salud Pública, 2008, 10(5), 831-839.

33. Bollen, K.A. Structural Equations with Latent Variables. New York: John Wiley \& Sons, 1989.

34. Arias, B. Desarrollo de un ejemplo de analisis factorial confirmatorio con LISREL, AMOS y SAS. En M. A. Verdugo, M. Crespo, M. Badia y B. Arias (Coords.), Metodología en la investigación sobre discapacidad. Introducción al uso de las ecuaciones estructurales Salamanca: INICO, 1989, 75120.

35. Cheung, G. W.; Rensvold, R. B. Evaluating goodness-of- fit indexes for testing measurement invariance. Structural Equation Modeling, 2002, 9(2), 233-255.

36. Crocker, P. R. E.; Bouffard, M.; Gessaroli, M. E. Measuring enjoyment in youth sport settings: A confirmatory factor analysis of the Physical Activity Enjoyment Scale. Journal of Sport and Exercise Psychology, 1995, 17, 200-205. 
37. Granero-Gallegos, A.; Baena-Extremera, A.; Martínez-Molina, M. Contenidos desarrollados mediante las actividades en el medio natural de las clases de Educación Física en Secundaria Obligatoria. Ágora, para la Educación Física y el Deporte, 2010, 12(3), 273-27.

38. Baena-Extremera, A.; Granero-Gallegos, A. Efectos de las actividades en la naturaleza en la predicción de la satisfacción de la Educación Física. Retos, 2015, 28, 9-14.

39. Baena-Extremera, A.; Granero-Gallegos, A.; Ortíz-Camacho, M. M. Quasi-experimental study of the effect of an Adventure Education program on classroom satisfaction, physical selfconcept and social goals in Physical Education. Psychologica Belgica, 2012, 52(4), 386-396.

40. Shanahan, D. F.; Franco, L.; Lin, B. B.; Gaston, K. J.; Fuller, R. A. The Benefits of Natural Environments for Physical Activity. Sports Medicine, 2016, 46(7), 989-995.

41. Sharma-Brymer, V.; Bland, D. Bringing Nature to Schools to Promote Children's Physical Activity Sports Medicine, 2016, 46(7), 955-962.

42. Kendzierski, D.; DeCarlo K. J. Physical activity enjoyment scale: two validation studies. Journal of Sport and Exercise Psychology, 1991, 13, 50-64.

43. Heesch, K. C.; Mâsse, L. C.; Dunn, A. L. Using Rasch modeling to re-evaluate three scales related to physical activity: Enjoyment, perceived benefits and perceived barriers. Health Education Research, 2006, 21 Suppl 1, 58-72.

44. Calogiuri, G.; Nordtug, H.; Weydahl, A. The Potencial of using Exercise in Nature as an Intervention to Enhance Exercise Behavior: Results from a Pilot Study. Perceptual and Motor Skills, 2015, 121(2), 350-370.

45. DiLorenzo, T.; Stucky-Ropp, R.; Vander, J.; Gotham, H. Determinants of exercise among children, II: A longitudinal analysis. Preventive Medicine, 1998, 27, 470-47.

46. Schneider, M. Intrinsic Motivation Mediates the Association Between Exercise-Associated Affect and Physical Activity Among Adolescents. Frontiers in Psychology, 2018, 9, 1151.

47. Sáez-Padilla, J.; Fuentesal, J. La formación universitaria en actividades físico-deportivas en el medio natural: situación actual y perspectivas de futuro. Tándem. Didáctica de la Educación Física, 2014, 45, 14-21.

48. Sáez-Padilla, J. La formación del profesorado de Educación Física de ESO en Andalucía en relación con las Actividades en el Medio Natural. Huelva: Servicio de Publicaciones, Universidad de Huelva, 2010. 